\title{
Abordagem Crítica nos Estudos \\ Organizacionais: Concepção de indivíduo sob a perspectiva emancipatória
}

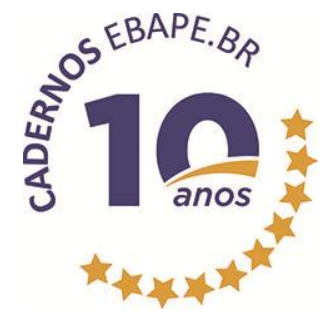

\section{Critical Approach in Organizational Studies: Conception of individual from the emancipatory perspective}

Anelise Rebelato Mozzato ${ }^{1}$

Denize Grzybovski ${ }^{2}$

\begin{abstract}
Resumo
O objetivo deste ensaio teórico é debater a necessidade de considerar racionalidades alternativas à instrumental nos Estudos Organizacionais, em favor do exercício da cidadania do indivíduo como ator social, com papel ativo e não sujeito da ciência e do mundo. São resgatados pressupostos teóricos dos Estudos Organizacionais críticos, no contexto paradigmático do humanismo radical, para responder porque fazer uma análise crítica. A justificativa é a de que a Ciência Social estabelecida tornou-se um meio legítimo de controle do mundo natural e a conduta humana. Apoiando-se em pressupostos teóricos ingênuos, na visão de Alberto Guerreiro Ramos, a Ciência da Administração se desenvolveu com base na racionalidade instrumental inerente à Ciência Social dominante no Ocidente, não sofrendo críticas até 1970 porque funcionou até ali. As críticas mais atuais não foram suficientes para romper a corrente principal, talvez porque a razão deslocada do psiquismo humano transformou-se em um atributo da sociedade. No entanto, há concepções epistemológicas alternativas ao funcionalismo e a abordagem crítica é caminho possível, podendo trazer avanços aos Estudos Organizacionais, constituindo um dos caminhos possíveis na busca da emancipação do homem em direção a uma sociedade melhor e mais justa.
\end{abstract}

Palavras-chave: Abordagem crítica. Emancipação do indivíduo. Racionalidade transformadora. Estudos organizacionais.

\section{Abstract}

This theoretical essay aims to debate the need for considering alternative rationalities with regard to the instrumental one in Organizational Studies, favoring the citizenship exercise of the individual as a social actor, with an active role and not as a subject of science and the world. Theoretical assumptions of the critical Organizational Studies are resumed, in the paradigmatic context of radical humanism, in order to say the reason why a critical analysis has to be performed. The

Artigo submetido em 29 de abril 2013 e aceito para publicação em 02 de setembro de 2013.

Agradecemos à FAPERGS pelo apoio financeiro à pesquisa que deu origem a este estudo.

1 Doutora em administração pela Unisinos; Professora titular da Universidade de Passo Fundo /UPF. Endereço: Rua Adolfo loureiro, 190, Apto. 401, Vera Cruz, CEP 99010 650, Passo Fundo - RS, Brasil. E-mail: anerebe@upf.br

2 Doutora em administração pela Universidade Federal de Lavras/UFLA; Professora titular da Universidade de Passo Fundo/UPF; Professora Convidada no Programa Stricto Sensu em Desenvolvimento da Universidade Regional do Noroeste do Estado do Rio Grande do Sul/UNIJUÍ. Endereço: Rua Uruguai, 1391, Apto. 402, Centro, CEP 99010-111, Passo Fundo - RS, Brasil. E-mail: gdenize@upf.br 
justification is that the established Social Science has become a legitimate way for controlling natural world and human behavior. Based on naive theoretical assumptions, according to Alberto Guerreiro Ramos' view, the Administration Science has evolved on the basis of the instrumental rationality inherent to the Social Science predominant in the West, not criticized until 1970 because it worked until then. More recent criticism was not enough to break the mainstream, perhaps because reason detached from human psyche has become an attribute of society. However, there are alternative epistemological conceptions with regard to functionalism and the critical approach is a possible pathway, being able to bring advances to Organizational Studies, constituting one of the possible pathways in the search for human emancipation towards a better and fairer society.

Keywords: Critical approach. Individual's emancipation. Transformative rationality. Organizational studies.

\section{Introdução}

O desenvolvimento da ciência da administração foi construído por quase todo o século XX sob influência dos pressupostos do paradigma positivista, no qual predominava o sistema industrial mecânico, o design organizacional rígido e a concepção de homem operacional como um recurso à produção. ${ }^{3}$ As circunstâncias sociais da época exigiam um homem operacional com características psicológicas que se conformavam às regras. A adoção de um método autoritário de alocação de recursos (humanos e não humanos) e a concepção de programas de treinamento como uma técnica de ajuste do indivíduo ao sistema foram descritas por Ramos (1984) como implicações desse modelo de homem para o design organizacional.

Dado o contexto complexo no qual se insere a sociedade do século XXI (BAUMAN, 2004; HARVEY, 2003; LIPOVETSKY, 2005; TENÓRIO, 2009) o objetivo deste artigo é contribuir com o debate sobre a necessidade de considerar racionalidades alternativas à instrumental nos estudos organizacionais em favor do exercício da cidadania do indivíduo como ator social, com papel ativo e não objeto da ciência e do mundo. Para tanto, resgatam-se pressupostos teóricos dos estudos organizacionais críticos, no contexto paradigmático do humanismo radical, para responder ao porquê fazer uma análise crítica.

Urgem como necessários os questionamentos, o pensamento crítico, a dialética e o pensar o impensável a partir do conceito da razão crítica, no sentido proposto por Faria e Meneghetti (2006), como categoria ética e elemento para a emancipação do homem e da sociedade. Com base num estudo bibliográfico entende-se a emancipação como o oposto da alienação, a qual limita a consciência do indivíduo em relação a sua existência e posição no mundo. Alienação, para Fromm (1983), refere-se à personalidade e é um fenômeno social em que a pessoa se sente como um estranho, impotente de se perceber como um ser humano total. Em indivíduos alienados, a consciência se reduz a imagem de um objeto e se torna socialmente uma coisa externa ao próprio sujeito. Essa visão paradigmática está presente na obra de Alberto Guerreiro Ramos, assim como na de outros autores que se opuseram ao paradigma funcionalista (ALVESSON e WILLMOTT, 1992), os quais são utilizados como elemento condutor do pensamento neste artigo.

Mesmo sendo reconhecido que há um debate nacional e internacional em torno da humanização nas organizações, o homem continua sendo tratado como um instrumento para se atingir os fins organizacionais

${ }^{3}$ O desenvolvimento da ciência da administração é um campo historicamente contestado (REED, 1998), mas Lex Donaldson tem mantido seu posicionamento em favor do desenvolvimento positivista, gerando profundo debate teórico. Para compreender tais abordagens, ver Donaldson (1985; 1996; 1997), Meyer, Tsui e Hinings (1993), Perrow (1994), Pfeffer (1993), Reed (1998), Schultz e Hatch (1996). 
(perspectiva weberiana). $\mathrm{O}$ questionamento sobre a realidade nos estudos organizacionais é aqui exposto pelo conceito do humanismo radical, o qual impõe questionamentos sobre a qualidade de vida das pessoas e das instituições sociais, com críticas ao modo capitalista que influencia o cotidiano das organizações (GOYA, 2013). Portanto, é na lógica inversa dessa realidade, da humanização como central, que se desenvolve este ensaio teórico.

Para melhor organização do texto, num primeiro momento são apresentados os paradigmas descritos por Burrel e Morgan (1979) e por Kuhn (2003), analisando-se a predominância paradigmática nos estudos organizacionais. Logo a seguir, detalha-se o paradigma do humanismo radical na perspectiva dos estudos organizacionais, em razão de ser visto como uma possibilidade alternativa à mainstream. Em seguida, são expostas questões relacionadas à racionalidade transformadora embasada no pensamento crítico, tendo em vista a emancipação. Diante da racionalidade transformadora, apresenta-se a possibilidade do indivíduo como ator (não como sujeito!) da realidade social e organizacional, salientando-se aspectos relacionados à necessária humanização.

Adiante, são feitas as considerações finais, ante o fato de que os estudos organizacionais críticos sobremaneira, as contribuições de autores brasileiros como Alberto Guerreiro Ramos, Fernando Prestes Motta e Maurício Tragtenberg ${ }^{4}$, entre outros -, são percebidos como possibilidade e desafio para um caminho alternativo ao desenvolvimento da administração no que tange à concepção de homem. Tais considerações finais apontam a necessidade da comunhão epistemológica entre racionalidade e historicidade para a criação e a formação do conhecimento científico reflexivo e emancipado nas teorias organizacionais.

\section{Os Estudos Organizacionais e a Predominância Paradigmática: iniciando o debate}

Por muito tempo, os estudos organizacionais desenvolveram-se orientados por um quadro teórico positivista e estrutural de interesse único de quem analisa (BURREL, 1994; HASSARD e PARKER, 1993), sob a influência de fortes correntes de pensamentos que refletem, na sua maioria, uma linha ortodoxa. O quadro fragmentado dos anos 1930 aos 1960 embasa plenamente uma análise crítica dos pressupostos teóricos weberianos, análise cujo objeto era fixo e foi gradualmente se transformando num conjunto de divergências linguísticas (modernismo). Os trabalhos de Jacques Derrida, em torno de um tipo de operação intelectual que desloca e relativiza a dialética hegeliana-marxista, denominada desconstrução, e de Michael Foucault indicaram novo momento nas ciências sociais (pós-modernismo), que evidencia a corrosão do fenômeno social que os teóricos organizacionais clássicos estavam tentando explicar (REED, 1998). Emerge um estado de "crise conceitual" nas teorias organizacionais (HASSARD,1995), pois a hegemonia da mainstream está sendo ameaçada por perspectivas intelectuais alternativas sem que haja um "sucessor óbvio" para a teoria de sistemas que marcou o projeto da modernidade (REED, 1998).

A interpretação de Hassard (1995) é a de que o poder de análise dos sistemas diminuiu da mesma forma que novos paradigmas da sociologia e da teoria das organizações emergiram, revelando as limitações conceituais e metodológicas do funcionalismo estrutural e da teoria social dos sistemas. A "abertura analítica" reconhece a dinamicidade do ambiente numa abordagem pluralista que abriga o diálogo entre ambiguidades e tensões,

${ }^{4}$ Maurício Tragtenberg é o autor que mais se identifica com a tradição da escola de Frankfurt, sendo o precursor da teoria crítica no Brasil com a obra Burocracia e ideologia. 
ao mesmo tempo em que evidencia um "mundo único, integrado" pela transgressão das fronteiras tradicionais (nações, culturas nacionais, tempo, espaço, narrativas) que modificam os contextos econômico, social, cultural, tecnológico e dos negócios (PARKER, 1995) e, por extensão, as narrativas. Esse momento reflexivo da área impõe aos pesquisadores a retomada do conceito de humanismo de Karl Marx - o qual afirma ser o homem a raiz dos sistemas vigentes nas instituições e das crenças tradicionais -, ou seja, a totalidade do homem vivo e concreto (FROM, 1983).

Os confrontos teóricos que se estabelecem promovem críticas àquilo que estava consolidado como verdade. Contudo, o mais importante é o espaço construído pelo projeto da modernidade à reflexividade dos contextos históricos e sociais, no qual o homem (e suas ações) é elemento central. A origem do debate está na crise da modernidade, que não é negada nem mesmo pelos modernistas. Essa crise impõe uma revisão das explicações sobre a sociedade atual, exigindo a construção de novas perspectivas analíticas muito além das cosméticas, uma vez que tais explicações não geram mudanças profundas no desenvolvimento da ciência da administração, devido a sua fragilidade conceitual (ver DiMAGGIO, 1995; DONALDSON, 1996; 1997; FORD, 2003; HICKSON, 1998; HODSON, 1998). Na era modernista, é notória a predominância paradigmática funcionalista nos estudos organizacionais, entre os quatro paradigmas apresentados por Burrel e Morgan (1979).

Na classificação de Burrel e Morgan (1979), o funcionalismo encontra-se na dimensão objetivista no sentido ontológico, pressuposto no qual predomina o realismo; isto é, a concepção de que o mundo existe independentemente da avaliação das pessoas e que os indivíduos são condicionados pelo contexto externo. No sentido epistemológico, está relacionado ao positivismo, que explica o mundo social através de relações causais e de regularidades que só podem ser verificadas empiricamente. Quanto à natureza humana, predomina o determinismo, segundo o qual a situação define a pessoa, que é controlada e condicionada, constituindo-se em produto do ambiente. Por fim, quanto à metodologia, é nomotético - por valorizar muito a pesquisa baseada em técnicas estatísticas (que testam hipóteses para compreender as relações de causa e efeito) - por implicar muito rigor e dar muita importância aos conceitos.

Diante do exposto, percebe-se que o funcionalismo apresenta pressupostos teóricos relacionados à regulação e à objetividade - orientando-se pelos métodos das ciências naturais para compreender os indivíduos e se apresentando como racionalista e pragmático -, com foco na estrutura, baseado em uma ordem social regulada. Nesse sentido, busca prover soluções práticas e objetivas calcadas no determinismo.

Como referem Burrel e Morgan (1979), há uma forma comum entre as diversas correntes do pensamento funcionalista, por mais que haja uma diferença substancial entre elas. Os teóricos funcionalistas estão ligados por uma visão compartilhada da realidade sociocientífica, proporcionando uma explicação de natureza regulada baseada em normas subjacentes de racionalidade utilitária, objetiva e preditiva. Essa racionalidade científica é utilizada para explicar a racionalidade essencial da sociedade, descrever o "comportamento normal" do mundo contemporâneo (FROMM, 1983) e tentar ordenar o mundo social similarmente ao mundo natural, como se isso fosse possível, sem efetivamente tentar promover uma revolução paradigmática.

Kuhn (2003) afirma que, em diferentes épocas, ocorreram transformações de paradigmas ("revoluções científicas") e que é justamente nessa transição de um paradigma para outro que a ciência se desenvolve e amadurece. "Ao nos ocuparmos da emergência de novas teorias, inevitavelmente ampliaremos nossa compreensão da natureza das descobertas" (Ibid, p. 94). 
Contudo, a aceitação de uma nova teoria requer flexibilidade para reavaliar fatos anteriores, atuais e futuros. Quando um pesquisador adota um novo paradigma é como se ele passasse a utilizar lentes inversoras, pois, "após uma revolução, os cientistas trabalham em um mundo diferente" (KUHN, 2003, p. 171). É assim que o autor contribui, sobremaneira, para o pensar a ciência. Ele refuta a linearidade do desenvolvimento científico, apontando que as próprias comunidades científicas necessitam despojar-se de seus próprios paradigmas em busca de revoluções científicas que atendam às necessidades da sociedade contemporânea.

As reflexões habermasianas deixam evidentes que o mundo social é constituído por parte da subjetividade humana através da linguagem e do discurso (HABERMAS, 2001). Segundo Hassard e Parker (1993), isso abre espaço para abordagens alternativas de análise organizacional. Nessa lógica alternativa, Ramos (1965) propõe um método de observação da realidade social ("redução sociológica") que permite ao analista abrir mão de seus julgamentos e conhecimentos prévios sobre o mundo circundante para só então compreender a realidade. Sua proposição, no entanto, só recentemente é retomada no contexto dos estudos organizacionais brasileiro.

Pesquisadores brasileiros, como Caldas (2005), Corso, Dalmoro, Faller et al. (2007) e Falcão Vieira e Caldas (2006) afirmam que o paradigma funcionalista não sustenta uma ciência revolucionária que busca a dialética, tendo em vista a emancipação humana (concepção marxista do capitalismo como sistema orgânico, [MARX, 1989]). Tal constatação também se encontra em Santana e Gomes (2007), que afirmam no Brasil ocorrer uma "paralisação" no paradigma funcionalista, principalmente, nas abordagens sistêmica e contingencial. Aqui se entende dialética como Habermas (2001), no sentido de que há uma estrutura de dominação inserida na linguagem do cotidiano organizacional e que, nessa busca, seria necessária a racionalidade comunicativa (HABERMAS, 2001) contrapondo-se à racionalidade instrumental weberiana do sistema capitalista, que se constitui numa forma de ação social dominante que aliena o homem (concepção fromminana, FROMM, 1983).

É importante revisar as noções apresentadas ainda em 1981 por Alberto Guerreiro Ramos, ${ }^{5}$ quando afirmou que a teoria das organizações é ingênua, por basear-se na "racionalidade instrumental inerente à ciência social dominante no Ocidente" (RAMOS, 1981, p. 1). É nisso que se fundamenta Tenório (2004) para propor renovação na gestão, contrapondo-se ao enfoque funcionalista e à racionalidade instrumental. Tal proposta também encontra respaldo nas críticas formuladas por Habermas (2001) ao discurso pós-modernista, por este querer gerar um novo conservadorismo, uma vez que se mantém dependente dos pressupostos hegelianos.

Contudo, os estudos organizacionais brasileiros estão atrelados ao desenvolvimento de uma visão crítica (FALCÃO VIEIRA e CALDAS, 2006) muito antes de 1980. Fernando C. Prestes Motta ${ }^{6}$ contribuiu sobremaneira para esse debate, bem como para o entendimento da sociedade moderna, a sociedade das organizações e da natureza da sociedade brasileira. Nos seus primeiros trabalhos fica evidente a busca por alternativas analíticas à concepção weberiana funcionalista, o que fez apoiando-se no pensamento de Proudhon em torno da autogestão (MOTTA, 1981).

5 Segundo Faria (2009, p. 51) Guerreiro Ramos é "um fenomenólogo crítico, não marxista, não frankfurtiano"; contribuindo, sobremaneira, com os estudos críticos em administração.

${ }^{6}$ Fernando Prestes Motta é um analista crítico que acreditava na abordagem psicanalítica como alternativa para analisar as organizações, em razão de que o psiquismo individual e coletivo começou a ser levado em conta, sobretudo, por Sigmund Freud. Assim, acreditava na possibilidade de novas teorias de caráter emancipatório. 
Um posicionamento crítico atual é encontrado nas obras de Alcadipani e Tureta (2009), Faria (2007; 2009), Martins e Martins (2012) e Tenório (2002; 2004; 2009). Santana e Gomes (2007), por sua vez, indicam caminhos para uma contra-hegemonia às pesquisas em administração, sem pretender destruir o funcionalismo, mas salientar que a dialética permite o amadurecimento da ciência. Para tanto, os referidos autores propõem articulações entre os vários campos do conhecimento e revisão de algumas posturas teóricas, em especial, nos estudos críticos sobre emancipação humana.

Por fim, parafraseando Kuhn (2003), afirma-se que uma "revolução científica" só ocorre com mudanças de ideias fundamentais inerentes a um campo científico, na qual as comunidades científicas necessitam se despojar de seus próprios paradigmas em busca daqueles que atendam às necessidades da sociedade atual. Levando em conta tais pressupostos paradigmáticos, os presentes no humanismo radical sustentados pela teoria crítica continuam sendo uma possibilidade de articulação entre diversos campos de conhecimento científico e a construção de espaços teóricos para conversações paradigmáticas.

\section{Humanismo Radical no debate: Possibilidade Paradigmática}

Apesar do resgate dos pressupostos teóricos dos estudos organizacionais críticos, no contexto paradigmático do humanismo radical (BURREL e MORGAN, 1979), este artigo não pretende buscar generalizações simplistas, mas, sim, contribuir com os critical management studies (CMS) [Estudos críticos em gestão (ECG)] pela perspectiva de racionalidades alternativas à instrumental, ciente de que esta não é a única.

Segundo Burrel e Morgan (1979), o paradigma que oferece modelos de análise, que valoriza uma prática menos determinista e regulada do sujeito, é aquele relacionado à sociologia da mudança radical, mais especificamente, o humanismo radical. O humanismo radical está voltado para a dialética e a emancipação humana individual e social, bem como à compreensão sobre como as pessoas podem ligar pensamento e ação (práxis) para transcender sua alienação (MORGAN, 2005). Como desafio operacional, a proposta deste paradigma estimula o conflito de ideias e a ruptura de "verdades" institucionalizadas, aprofundando a investigação dos conflitos estruturais profundamente arraigados, das contradições estruturais e dos modos de dominação. Trata-se de uma investigação movida principalmente pelo interesse na emancipação humana, com o propósito de libertar o homem daquilo que o limita na ação.

Tal pressuposto está amparado no fenômeno da alienação da personalidade (FROMM, 1983) impressa no mundo capitalista, no qual o sujeito "aliena suas forças na relação com o trabalho, com as coisas que consome, com o Estado, seus semelhantes e consigo mesmo" (GOYA, 2013). Nesse sentido, Marx (1989) denunciou a alienação do homem, demonstrando que o sistema capitalista de produção era central para isso, e chamou a atenção para a necessária autoconsciência, a qual poderia modificar a sociedade. Mais tarde, os estudos de Marx deixaram de ter essa perspectiva idealista, na medida em que ele passou a interpretar de maneira mais realista a natureza do mundo social, contemplando a necessária presença do Estado e de um “capitalismo orgânico" (MARX, 1989). Perspectiva orientada, primordialmente, na crítica e na dialética.

No sentido epistemológico, o humanismo radical está relacionado ao antipositivismo, no qual o conhecimento é explicado pela experimentação pessoal das pessoas em suas relações, entendendo o mundo como essencialmente relativista. Quanto à natureza humana, predomina o voluntarismo que considera que as pessoas possuem livre-arbítrio, não se constituindo em simples produto do ambiente, sendo, pelo contrário, vistas como ativas, reflexivas, críticas e autônomas, ocupando centralidade. Por fim, quanto à metodologia, a abordagem caracteriza-se como ideográfica, a qual, apesar de valorizar a pesquisa com rigor científico, não 
tem bases rígidas, enfatizando a natureza relativa do mundo social e percebendo que este só pode ser entendido através da investigação da realidade e das constatações subjetivas tal como se apresentam.

Contudo, há duas vertentes de discurso no humanismo radical. De um lado, o idealismo subjetivista derivado da filosofia de Husserl, Kant e Fichte. De outro, o idealismo objetivista derivado, sobretudo, do trabalho de Hegel. Porém, a filosofia hegeliana também apresenta duas vertentes. De um lado, aqueles que seguiram integralmente sua filosofia (hegelianos de direita). De outro, os "jovens hegelianos" (hegelianos de esquerda), entre os quais se encontra Marx (1818-1883).

Percebe-se que o humanismo radical trabalha tanto com a corrente subjetivista como com a objetivista, evidenciando a existência de quatro orientações teóricas principais (solipsismo, existencialismo francês, individualismo anarquista e teoria crítica) (BURREL e MORGAN, 1979). Dentre essas orientações teóricas, a teoria crítica é a mais desenvolvida, havendo três escolas de pensamento: sociologia lukacsiana, ${ }^{7}$ sociologia gramsciana $^{8}$ e escola de Frankfurt. ${ }^{9}$ A teoria crítica "pretende expressar a emancipação dos indivíduos e promover a conscientização crescente da necessidade de uma sociedade em que os interesses coletivos prevaleçam sobre os individuais, em que os indivíduos sejam sujeitos de sua própria história, escrevendo-a coletivamente" (FARIA, 2009, p. 423).

Ao contrário da sociologia da regulação, à qual está ligado o paradigma interpretativista e funcionalista, o humanismo radical volta-se à sociologia da mudança radical para tentar modificar o mundo, não só compreendê-lo. Para tanto, os teóricos críticos acreditam nas potencialidades humanas, demonstrando claro interesse pela liberdade do espírito humano, focando a consciência como possibilidade de emancipação contra a alienação. Alienação no sentido defendido por Marx (1989), aquela que tem o sistema capitalista de produção como central, numa condição objetiva do capitalismo independente da forma de pensar, não havendo autoconsciência.

A proposta do humanismo radical é apresentar uma nova abordagem para se ver e viver no mundo, a qual vai além da perspectiva funcionalista predominante. No que tange aos estudos organizacionais, tal paradigma possibilita outra perspectiva de se ver e se trabalhar nas organizações e de perceber como elas se inserem e influenciam no contexto social, possibilitando uma visão de mundo mais crítica e com possibilidade emancipatória. O paradigma humanista radical focaliza a atenção em aspectos políticos e exploradores da vida organizacional.

Percebe-se o crescente número de trabalhos científicos na linha dos estudos críticos em gestão também no Brasil, a partir da década de 1990 (PAULA, 2007). Em outros países, os ECGs ainda são superados pela ortodoxia, mas em países mais desenvolvidos estão sendo bem aceitos, como se constata na edição especial

${ }^{7}$ A sociologia lukacsiana constitui-se na primeira escola de pensamento crítico, a partir do início da década de 1920, influenciada pelo neoidealismo, Luckács reenfatizou a influência de Hegel sobre Marx e procurou desenvolver uma teoria crítica como alternativa ao marxismo ortodoxo da época. Luckács salientava a consciência de classe, invocando uma dialética onipresente para mudar o mundo.

A sociologia gramsciana teve ênfase no início da década de 1960 nos meios acadêmicos do Ocidente, tendo claramente orientação para a ação e a mudança radical, a "filosofia da práxis".

9 A Escola de Frankfurt é representada por estudiosos como Horkheimer, Adorno, Benjamim, Fromm, Lowenthal, Marcuse e Habermas, entre outros, baseados em fundamentos ontológicos e epistemológicos das teorias dos "jovens hegelianos", como Marx. Esses autores buscam, pela revolução da consciência (opondo-se à alienação), bases para a mudança social necessária perante a natureza da sociedade capitalista, abarcando uma filosofia crítica com objetivos claramente emancipatórios (BURREL e MORGAN, 1979). 
de setembro de 2007 do periódico Organization Studies. Mais enfático, Reed (1998, p. 91) defende um posicionamento a favor dos teóricos organizacionais críticos, para que desenvolvam uma rede de debates críticos internos e externos às tradições narrativas, que, assim, indelevelmente, conformam a evolução do campo.

A ideia de "conversação" também se torna explícita, pois os paradigmas podem e devem "conversar" entre si ("casamento" das teorias organizacionais), momento em que a dialética faz-se necessária na perspectiva de uma ciência com consciência. Para tanto, o enfoque multi e transdisciplinar no entendimento das organizações e da sociedade também se faz necessário. Apesar do interesse crescente pela interdisciplinaridade, não basta a simples aproximação ou justaposição das disciplinas, mas a eliminação de fronteiras entre as problemáticas (transdisciplinaridade) que se apresentam, instaurando uma comunicação fecunda (JAPIASSU, 2013).

O homem deve assumir posição de tutor da natureza, tomando cuidado com o que manipula e instaurando conduta ética. Refere Meneghetti (2004) que é necessário possibilitar mudanças na forma como se faz ciência sem, contudo, cair na primazia dos fatos, impedindo que a razão se torne "prisioneira" do próprio formalismo.

Nesse sentido, pode-se afirmar que há uma revolução paradigmática em curso (SOUSA SANTOS, 2000), até porque não se aceita mais a mera reprodução do conhecimento. A teoria crítica compromete-se com a libertação dos sujeitos das relações de poder, inclusive, pela sua própria subjetividade (FOURNIER e GREY, 2006) e torna primordial a dialética, sobretudo, fazendo-se necessários novos caminhos na busca da emancipação humana, o que exige a tomada de consciência do papel de cada um no mundo. Dessa maneira, a teoria crítica constitui possibilidade paradigmática, trazendo avanços e inovações para a área dos estudos organizacionais e a proposta por uma racionalidade transformadora.

\section{Racionalidade Transformadora: Estudos Organizacionais Críticos e Emancipação}

Na perspectiva da emancipação contra a alienação, nesta seção pretende-se fazer alusões à necessidade de entender-se e buscar outras racionalidades que não apenas a instrumental. Segundo Freire (1979, p. 33), o desenvolvimento de uma consciência crítica permite ao homem transformar a realidade, uma necessidade cada vez mais urgente. Nessa lógica, os estudos críticos organizacionais buscam a manutenção da crítica e a orientação pelo princípio da transformação social e da emancipação do homem na sociedade.

Mesmo ciente de que não existe apenas uma via para a emancipação, faz-se necessário pensar o humano fora da racionalidade técnica. Do ponto de vista da racionalidade transformadora, em consonância com os estudos organizacionais críticos, que busca o entendimento das contradições da sociedade por meio da dialética, é possível pensar em outras possibilidades de ver o indivíduo que não seja apenas segundo o paradigma positivista predominante. Morin (1991) afirma crer que o modelo ideal de funcionalidade e de racionalidade não é apenas um modelo abstrato, mas um modelo prejudicial - prejudicial para os que estão nas administrações e para o conjunto da vida social.

De fato, no atual contexto, são desejáveis ações sociais transformadoras, que possibilitem às pessoas serem sujeitos ativos e autônomos no contexto social em que vivem. É nesse sentido que se torna evidente a contribuição dos ECG para a administração e seus estudos organizacionais, a exemplo do paradigma humanista radical. Refere Meneghetti (2004, p. 15) que o pensamento crítico "não é mera sugestão de 
temáticas para serem estudadas na Teoria das Organizações, mas entendimento sobre o método materialista dialético nas análises dessas temáticas nas organizações". O autor defende que a racionalidade instrumental que se procura instituir nas organizações em razão da tendência funcionalista não deveria mais ocorrer.

Habermas (1997) critica o fato de a racionalidade humana estar sendo utilizada na direção oposta à da emancipação dos indivíduos, num processo em que a razão se torna uma ideologia que atende aos interesses de uma minoria. Refere que o progresso deveria ser sempre um meio utilizado para beneficiar as pessoas indistintamente, sem todos os males que causa, como a destruição da natureza e a injustiça social.

A questão das crescentes desigualdades sociais também é denunciada por Chanlat (2000), evocando questões relacionadas à ética, liberdade, equidade, justiça, afetividade, solidariedade e história, em que o homem se constitui no ator principal que participa da transformação do mundo. Em obra escrita posteriormente, o autor aborda que "o que sempre me interessou foi o ser humano, pois as organizações são seres humanos em relação, não somente processos, técnicas” (Id., 2006, p. 9).

Nesse sentido, Sousa Santos (2000) fala da possível hermenêutica crítica da epistemologia dominante, evocando um paradigma de conhecimento prudente (paradigma científico) para uma vida decente (paradigma social). Refere ainda que a humanidade deve procurar um desequilíbrio dinâmico que penda para a emancipação, a qual se sobreponha à regulação.

A principal tarefa da administração é proporcionar um desenvolvimento e um mundo melhor para todos, acredita Aktouf (1996). A principal tese da sua obra A administração entre a tradição e a renovação é a convicção de que a administração deve sofrer uma renovação, uma mudança radical, para a adoção de novos modelos. Isso significa uma "administração renovada". O autor critica a administração tradicional (ou clássica) e apresenta propostas que possibilitem, de fato, uma "administração renovada". A obra contribui, sobretudo, no sentido de provocar e propiciar espaço para a reflexão sobre modelos renovadores de gestão. Refere que se fazem necessárias rupturas com o passado para traçar os contornos da gestão do futuro, pois "a gestão já não pode ser concebida como uma coleção de técnicas e receitas” (1996, p. 99).

No que tange à relação entre o lucro almejado pelas organizações e a sustentabilidade na dimensão social necessária, Aktouf (1996, p. 17) afirma que se faz necessário às organizações obterem lucro, mas, "sem cair nos excessos do maximalismo tradicional que conduz ao sofrimento, degrada e realmente destrói tanto o ambiente interno da empresa (os empregados) quanto o ambiente externo (o meio ambiente)". Na perspectiva crítica primordial, há necessidade do trabalho na sociedade e da intervenção do homem na natureza, que se constitui no trabalho. Porém, isso deve ocorrer no sentido de sobrevivência da humanidade, não para estabelecer diferenças sociais (VIEIRA PINTO, 1979).

Além dos processos de valorização do capital, faz-se necessário olhar o sujeito trabalhador em sua relação com o trabalho, libertando-se da lógica linear. Daí a importância da dialética e dos estudos críticos em administração, por meio das quais a realidade pode e deve ser vista em vários sentidos, até mesmo podendo ser contraditória. Quando a administração propõe-se a trabalhar segundo o paradigma crítico, está se propondo a buscar novos "olhares" para os fenômenos organizacionais, possibilitando a criação de novas racionalidades em busca da emancipação. Percebe-se, então, a necessidade de se vislumbrar uma perspectiva mais humanizada para os estudos organizacionais, como uma via para tornar as organizações espaços em que a emancipação humana tenha lugar. Nessa perspectiva, Falcão Vieira e Caldas (2006, p. 64) afirmam que: "O espaço dos estudos organizacionais no Brasil nos possibilita a oportunidade de romper com a dependência. 
Permite-nos pensar que só é possível discutir emancipação quando resgatarmos a consciência da nossa posição relativa no mundo, e que dela decorrem outras relações no âmbito interno de nossas organizações".

Concorda-se com os autores quando dizem acreditar que a abordagem crítica é um dos possíveis caminhos para a emancipação humana em direção a uma sociedade melhor e mais justa. Como bem pontuam Falcão Vieira e Caldas (2006) e Paula e Maranhão (2009), os estudos críticos são orientados pelo princípio da transformação social e da emancipação. Para tanto, ações coletivas fazem-se necessárias. É justamente desse modo que a pedagogia crítica pode ser apontada como uma forma coletiva de resistência, como refere Freire (2005, p. 58): "os homens se libertam em comunhão".

Nessa lógica, novas possibilidades metodológicas também necessitam de legitimação no meio acadêmico e de questionamentos quanto a sua ortodoxia, pois é através da pesquisa, do trabalho científico sério, que se pode vislumbrar uma racionalidade transformadora, na qual o homem realmente ocupe posição na sociedade como sujeito ativo e não passivo, saindo da posição de alienação. Assim, refere Bourdieu (1989, p. 26): “a pesquisa é uma coisa demasiado séria e demasiado difícil para se poder tomar a liberdade de confundir a rigidez, que é o contrário da inteligência e da invenção, com o rigor, que se ficar privado deste ou daquele recurso entre os vários que podem ser oferecidos pelo conjunto das tradições intelectuais da disciplina."

Tanto Bordieu (1989) como Morin (1991) e Sousa Santos (2000) revelam-se contra a fragmentação, a favor de um pensar relacional: o todo e as partes, a unidade e o diverso. Nesse mesmo sentido, Vieira Pinto (1979, p. 326) entende que "o trabalho científico não pode ser considerado isoladamente, nem em abstrato, mas só se torna entendido quando o situamos no conjunto concreto do qual é uma manifestação. Esta lição tem importância capital para a formação da consciência do cientista crítico". "A ciência só cria as condições do próprio desenvolvimento se ajuda a criar as condições de desenvolvimento das demais formas de trabalho nacional, especialmente as que transformam a face da realidade" (VIEIRA PINTO, 1979, p. 336-337).

Aktouf (2004), em sua obra Pós-globalização, administração e racionalidade econômica: a síndrome do avestruz, faz uma crítica humanista à ideologia única globalizada, na qual a globalização acaba justificando a busca por vantagens egoístas que desconsideram a finalidade humana da atividade econômica. Compartilhase a ideia do autor quando este denuncia que as pessoas estão deixando de lado sua plenitude como ser humano por falta de reflexão em relação à busca do lucro máximo em mercados autorregulamentados e de concorrência ilimitada, que almejam a realização sem considerar a natureza sociocomunitária do homem, atentando apenas para o estreito utilitarismo.

À medida que se estudam os conceitos desenvolvidos por Alberto Guerreiro Ramos, em especial o de homem parentético, torna-se evidente a importância destes para os estudos organizacionais, emergindo uma nova concepção de homem na sociedade: indivíduo ator e não sujeito (ingênuo) dos acontecimentos sociais. Nessa perspectiva, o indivíduo é dotado de reflexividade e criticidade, encontrando-se no caminho da busca do homem parentético e, por consequência, da emancipação. De tal modo, torna-se possível vislumbrar a construção de uma racionalidade transformadora.

Diante de tal perspectiva, a alienação e o adestramento social não se justificam. Na ótica transformadora, Freire (2005) evidencia a educação como central para a emancipação, defendendo a liberdade e a autonomia humana por meio da consciência crítica. Como afirmam Paula e Maranhão (2009, p. 474); "a pedagogia crítica freireana emergiu como um caminho tanto para analisar como para fomentar as ações coletivas, constituindo-se em um referencial valioso para os pesquisadores alinhados com o humanismo crítico nacional". 
Nesse sentido, a racionalidade transformadora partiria da consciência de uma guerrilha intelectual interna; a concretização de um novo pensar, balizado na emancipação do homem. Além disso, requereria um despertar, um olhar que vislumbrasse aquilo que a sociedade pode ser, mas ainda não é, um interesse, um questionamento natural e a contínua busca pela transformação da sociedade em algo melhor.

De acordo com Tenório (2002), a teoria crítica se distingue da teoria tradicional por acreditar que o indivíduo não pode ser visto isolado do seu contexto social, havendo a necessidade de exercício dialético de aprendizado e reflexão, teórico e prático. Para o autor, em consonância com Alberto Guerreiro Ramos, é só com essa tomada de consciência que se podem buscar novos caminhos, rompendo assim com as barreiras da alienação, constituindo-se uma racionalidade de liberdade, uma nova racionalidade: a transformadora.

Segundo Alvesson e Willmott (1992), as ciências sociais podem e devem contribuir para liberar as pessoas de ideologias e tradições desnecessárias que inibem e distorcem as oportunidades de autonomia. Também Faria e Meneghetti (2006) entendem que existe uma ideologia dominante que torna parcial a consciência dos indivíduos em relação ao social e que através da emancipação os indivíduos podem vislumbrar a autonomia, tomando consciência da sua existência e posição no mundo. Como salienta Faria (2009), a teoria crítica pode combater o individualismo e as diferentes formas de dominação que inviabilizam a emancipação humana, pois a razão instrumental não direciona o homem à emancipação.

Dado o exposto, percebe-se que a racionalidade transformadora necessita ser reconstruída, dependendo do rompimento com as barreiras da ingenuidade e da ilusão. Daí se percebem as dificuldades que essa reconstrução emancipatória enfrenta, já que o pensamento crítico é uma construção que demanda tempo e exige, em primeiro lugar, consciência de que a história não é imutável e se encontra em constante construção. Concorda-se com Freire (1979, p. 33) quando afirma: "O mundo não é. O mundo está sendo". Por conseguinte, "o desenvolvimento de uma consciência crítica que permite ao homem transformar a realidade se faz cada vez mais urgente" (Id., 1979, p. 85). Acredita-se que por meio da práxis, termo cunhado pelo autor, o mainstream funcionalista pode ceder espaço para outras alternativas epistemológicas mais recentes e apropriadas aos tempos atuais.

\section{O Indivíduo como Ator Organizacional e Social: a Humanização}

A dialética imposta pela complexidade no século XXI traz à luz a visão de muitos autores. Percebe-se que os teóricos positivistas da administração compreendem o indivíduo como sujeito social, enquanto os teóricos críticos compreendem o indivíduo como ator humano e social, não como sujeito atônito diante da realidade tal como se apresenta. Como argumenta Ramos (1981), a psique humana deve ser o aspecto central na construção de uma "nova teoria das organizações".

Concorda-se com Sousa Santos (2005) quanto a necessidade de conferir às ciências sociais uma nova centralidade na busca de um novo senso comum. Emerge a necessidade de ações sociais transformadoras no ambiente organizacional que possibilitem às pessoas serem sujeitos ativos (atores) e autônomos no contexto social em que vivem. Para Aktouf (1996), é necessário passar da alienação à reabilitação do sujeito ator numa "cultura" compartilhada, porque a alienação adoece o homem. Ele afirma que a mudança na maneira de gestão, em que se considere o humano e o social, não é um sentimentalismo ou modismo, mas questão de sobrevivência das empresas. 
Nos estudos organizacionais críticos, o indivíduo ocupa papel central, devendo ser considerado ator principal e não, sujeito das transformações, isto é, humano. Nessa ótica, Meneghetti (2004, p. 4) considera o humanismo um objetivo a ser perseguido, e o faz mesmo levando em conta que "em cada época isso tenha sido feito, as condições materiais e as limitações humanas impossibilitaram sua concretização. Embora sabendo que o atual contexto histórico limita a concepção e a consciência da necessidade de persegui-lo, somente a busca e a reformulação constante da concepção de humanismo pode levar à sua consolidação."

É justamente desse modo que se percebe a teoria crítica, a exemplo do paradigma humanista como uma possibilidade nos estudos das organizações, uma vez que se propõe a tentar entender os problemas organizacionais considerando o contexto e a história, visando cada vez mais a uma sociedade humanizada no sentido da emancipação. Japiassu (2013, p. 1) enfatiza a necessidade da construção contemporânea de uma "visão ao mesmo tempo transcultural e transhistórica, permitindo-nos compreender o mundo atual em sua complexidade e o ser humano em suas ambiguidades".

Chanlat (2000) salienta a importância da compreensão da ação humana, da cooperação, da solidariedade e do homem como ator efetivo, que denuncia a dominação. Contudo, o homem não é respeitado como tal, o que o leva ao sofrimento, pois ele sempre foi visto como um meio para alcançar um fim. Entretanto, "ele carrega em si sua própria finalidade" e não raras vezes segue um processo de desumanização que o torna alienado no trabalho (AKTOUF, 1996, p. 239). Eis a necessidade de mudança de mentalidade nas práticas administrativas, nas quais o ser humano deve constituir-se como central, dando abertura para uma gestão renovada (TENÓRIO, 2002; 2004).

Mais recentemente, até as próprias teorias ortodoxas, falam da necessária centralidade no homem, considerando-o como um todo. No entanto, essa questão não é levada a cabo de maneira efetiva, seguindo apenas a racionalidade técnica, o que não é suficiente para romper o mainstream. Nessa lógica, tal centralidade no homem faz parte do discurso pós-moderno, apenas a serviço do capital. Assim, a razão deslocada do psiquismo humano transformou-se apenas num atributo da sociedade, e não, na verdadeira humanização ao se conceber o sentido do trabalho e do trabalhador, o que culminaria na emancipação.

Aktouf (2004) orienta no sentido de que a necessária e radical mudança na maneira de raciocinar a respeito das organizações e da gestão está vinculada à percepção dos fatores de sucesso atrelados à filosofia de gestão e à concepção de trabalho e de trabalhador. "É aí que está o ponto crucial das contradições que perpassam as teorias e os métodos administrativos. O empregado do "fazer mais, mais rápido" e da obediência passiva não é o empregado capaz de adesão ativa, de vigilância pessoal, de iniciativa e de criatividade a todos os instantes e em todos os níveis"(AKTOUF, 2004, p. 209).

Tal afirmação do autor traz a tônica da contradição inerente ao capitalismo hodierno. Como refere Ramos (1999, p. 130), "a história contemporânea está de fato prenhe de um novo tipo de homem, a quem eu, em algum lugar, chamei de "homem parentético"'. O autor fala de três modelos de homem: o operacional, o reativo e o parentético. O primeiro, o homem operacional, é aquele visto como recurso organizacional que traz resultados; o segundo é aquele modelo de homem que foi desenvolvido pela escola das relações humanas, trata do ajustamento do indivíduo ao ambiente organizacional, o qual, desse modo, passa a ser preocupação central; por fim, o homem parentético, que possui consciência altamente desenvolvida e que, "no esforço de ser autônomo, não pode ser explicado pela psicologia do conformismo, da mesma forma que os indivíduos que se comportam de acordo com os modelos reativo e operacional” (Ibid., p. 135). 
Para Ramos (2001), ao ter o homem parentético como alternativa contemporânea, a própria teoria organizacional emancipa-se por não mais poder legitimar a racionalidade funcional da organização, como tem acontecido amplamente. De fato, a imagem de homem parentético - aquele que observa, reflete e examina o contexto da vida - leva à necessidade que se tem de pensar a respeito do papel dos indivíduos nas organizações e também sobre a emergência de uma nova concepção de homem na sociedade. Nesse modelo de homem organizacional está a "atitude crítica, que suspende ou coloca entre parênteses a crença do mundo comum, permitindo ao indivíduo alcançar um nível de pensamento conceitual e, portanto, de liberdade" (RAMOS, 1984, p. 8).

Apresentada a exposição, tornam-se evidentes contribuições importantes para os estudos organizacionais críticos também de autores brasileiros, como Alberto Guerreiro Ramos, Fernando Prestes Motta e Maurício Tragtenberg, entre outros mais atuais como José Henrique de Faria e Fernando G. Tenório, que comungam de uma visão crítica e não instrumental das organizações. Tais estudos procuram denunciar o positivismo ortodoxo e também oferecer fortes bases conceituais para a adoção de uma visão crítica nos estudos organizacionais. Ramos (1965) enfatiza a necessidade dos teóricos organizacionais buscarem a libertação da servidão intelectual e transcender a condição de repetir e copiar as teorias ditas prontas e verdadeiras. Nessa perspectiva, evidencia o papel do ator organizacional como indivíduo liberto da sua própria alienação, que pensa e interfere na realidade das organizações e, por consequência, na sociedade.

\section{Considerações Finais}

Neste artigo, a pós-modernidade é reconhecida como um sinal de uma nova época da investigação sociológica que requer a utilização da abordagem crítica nos estudos organizacionais, com vistas à emancipação da ciência da administração. A análise aqui apresentada revela que os estudos organizacionais têm sido desenvolvidos pela influência do positivismo, mas aponta para a necessidade da junção epistemológica de diferentes racionalidades para a criação e formação do conhecimento científico reflexivo em administração.

Diante da realidade primordial de humanização, é preciso garantir aos indivíduos que atuam nas organizações, o exercício da autorreflexão, para que sejam vistos como sujeitos ativos e não apenas como sujeitos da ciência e do mundo. Como acreditam muitos autores aqui citados, pensa-se a emancipação como um processo de superação da alienação, onde as pessoas são vistas como atores sociais e organizacionais. Os estudos organizacionais requerem racionalidades alternativas à preponderante na ortodoxia, perante a possibilidade de prover mudanças no fazer ciência da administração, enfatizando um olhar responsável em relação ao ser humano como um ser complexo e total.

O contexto no qual a ciência da administração se desenvolve mudou, do século XX (orientada pela ordem, pela maximização dos resultados e pela instrumentalidade da razão) para o século XXI (marcado pelo individualismo, "amor líquido", globalização dos mercados e da sociedade, num mundo cada vez mais fragmentado e incerto, sem consonância com o desejo de ordem proposto pela ortodoxia funcionalista) é o contexto pós-moderno. Os estudos críticos em administração são polêmicas vertentes nos estudos organizacionais que anseiam por reflexões mais aprofundadas, pretendendo-se em consonância com a perspectiva crítica. A teoria crítica é uma abordagem alternativa ao modo de gerar conhecimento, podendo trazer avanços aos estudos organizacionais, constituindo-se num dos caminhos possíveis na busca da emancipação do homem, na direção de uma sociedade melhor e mais justa e harmônica. 
A ideia da transdisciplinaridade aparece como elemento novo no processo de reformulação e racionalização. Justamente em razão dessa "novidade" (questionar o já instituído), o medo aparece e a recusa prevalece na maioria das vezes, como afirma Japiassu (2013). "Nada causa tanta destruição quanto a obsessão de uma verdade considerada como absoluta".

É justamente o desenvolvimento da ciência da administração sob influências direcionadoras (que impossibilitam uma perspectiva emancipatória aos indivíduos e à sociedade) que deve ser superada. Há concepções epistemológicas alternativas ao funcionalismo ortodoxo, especialmente, racionalidades que se impõem e devem ser consideradas e pensadas como possíveis na perspectiva de mudanças no fazer ciência com responsabilidade em relação ao ser humano e à sociedade. É o caso da racionalidade substantiva proposta por Guerreiro Ramos, entre outras apresentadas pelos teóricos críticos contemporâneos, os quais enfrentam o pensamento hegemônico na área.

O pensamento ortodoxo tem medo do novo. No entanto, "precisamos de pensadores que saibam sonhar e de sonhadores que saibam pensar" (JAPIASSU, 2013, p. 7). Urge um novo pensamento para os problemas da atualidade. Morin (1991) defende um pensamento capaz de enfrentar o desafio da complexidade do real, tendo em vista que simplificar não é mais possível. Afinal, "um saber que não se questiona constitui um obstáculo ao avanço dos saberes" (JAPIASSU, 2013, p. 5).

Aqui não se tem a pretensão de apresentar alternativas prontas, estruturadas ou palavras de ordem. Almejase, sim, apresentar certos contributos e formular questionamentos que possam auxiliar na busca de uma sociedade mais humana e emancipada. Para tanto, uma visão mais complexa e crítica na administração faz-se necessária por meio dos estudos organizacionais, o que permitirá avanços e inovações para a própria área, pois a dialética permite o amadurecimento da ciência. Os novos estudos que envolvam a teoria crítica são entendidos como pertinentes, sobretudo, tendo como foco o desenvolvimento de uma consciência emancipatória no contexto das organizações, firmando a posição do indivíduo como ator social. Em especial, o entendimento é o de que se encontra em aberto o espaço para estudos empíricos sobre as práticas de gestão de pessoas e o comportamento organizacional, na perspectiva teórica aqui apresentada.

\section{Referências}

AKTOUF, O. A administração entre a tradição e a renovação. Tradução: Roberto Fachin e Tânia Fischer. São Paulo: Atlas, 1996.

2004

Pós-globalização, administração e racionalidade econômica: a síndrome do avestruz. São Paulo: Atlas,

ALCADIPANI, R; TURETA, C. Perspectivas críticas no Brasil: entre a "verdadeira crítica" e o dia a dia. Cadernos EBAPE.BR, v. 7, n. 3, p. 504-508, 2009.

ALVESSON, M.; WILLMOTT, H. Critical theory and management studies: an introduction. In: ALVESSON, M.; WILLMOTT, H. (Org.). Critical Management Studies. London: Sage, 1992.

BAUMAN, Z. Amor líquido: sobre a fragilidade dos laços humanos. Rio de Janeiro: Jorge ZAHAR Editor, 2004.

BOURDIEU, P.O poder simbólico. Rio de Janeiro: Bertrand Brasil, 1989. 
BURREL, G. The contribution of Jurgen Habermas (Modernism, postmodernism and organizational analysis, part four). Organizations Studies, v. 15, n. 1, p. 1-18, 1994.

; MORGAN, G. Sociological paradigms and organizational analysis: elements of the sociology of corporate life. Aldershot, UK: Ashgate, 1979.

CALDAS, M. P. Paradigmas em estudos organizacionais: uma introdução à série. Revista de Administração de Empresas, v. 45, n. 1, p. 53-57, jan./mar. 2005.

CHANLAT, J. F. Ciências sociais e management: reconciliando o econômico e o social. Tradução: Ofélia de Lanna Sette Tôrres. 2.ed. São Paulo: Atlas, 2000.

Ciências sociais e management. Revista de Administração da FEAD, v. 3, n. 2, p. 9-17, dez. 2006.

CORSO, K. B. et al. Dominância epistemológica em estudos do campo: são ainda os administradores positivistas? In: ENCONTRO DA ANPAD, 31., 2007. Rio de Janeiro. Anais... Rio de Janeiro, 2007. 1 CD-ROM.

DiMAGGIO, P. J. Comments on "what theory is not”. Administrative Science Quarterly, v. 40, p. 391-397, 1995.

DONALDSON, L. In defense of organizational theory: a reply to critics. Cambridge: Cambridge University, 1985.

For positive organization theory: proving the hard core. London: Sage, 1996.

A positivist alternative to the structure-action approach. Organization Studies, v, 18, n. 1, p. 77-92, 1997.

FALCÃO VIEIRA, M. M.; CALDAS, M. P. Teoria crítica e pós-modernismo: principais alternativas à hegemonia funcionalista. Revista de Administração de Empresas, v. 46, n. 1, p. 59-70, jan./mar. 2006.

FARIA, J. H. (Org.). Análise crítica das teorias e práticas organizacionais. São Paulo: Atlas, v. 1, 2007.

Teoria crítica em estudos organizacionais no Brasil: o estado da arte. Cadernos EBAPE.BR, v. 7, n. 3, p. 509515, set. 2009.

; MENEGHETTI, F. K. Razão tradicional e razão crítica: os percursos da razão no ensino e pesquisa em administração na concepção da teoria crítica. In: ENCONTRO DA ASSOCIAÇÃO NACIONAL DE PÓSGRADUAÇÃO E PESQUISA EM ADMINISTRAÇÃO (EnANPAD), 29., 2005. Brasília, DF. Anais... Brasília, DF: [s.n.], 2006. 1 CD-ROM.

FORD, E. W. et al. A pesquisa que faz diferença. Revista de Administração de Empresas, v. 43, n. 4, p. 86-101, out./dez. 2003.

FOURNIER, V.; GREY, C. Na hora da crítica: condições e perspectives para estudos críticos de gestão. Revista de Administração de Empresas, v. 46, n. 1, p. 71-86, jan./mar. 2006.

FREIRE, P. Educação e mudança. Tradução: Moacir Gadotti. Rio de Janeiro: Paz e Terra, 1979.

Pedagogia do oprimido. 40. ed. Rio de Janeiro: Paz e Terra, 2005.

FROMM, E. Conceito marxista do homem. 8. ed. Rio de Janeiro: Zahar, 1983.

GOYA, W. O valor espiritual da razão, segundo Erich Fromm. Revista On-line IPOG Especialize, Goiânia, n. 5, 2013. 
HABERMAS, J. Teoría de la acción comunicativa: complementos y estudios previos. Madrid: Cátedra, 1997.

Teoria de la acción comunicativa. Tomo I. Racionalidad de la acción y racionalización social. Madrid:

Taurus Humanidades, 2001.

HARVEY, D. Condição pós-moderna. São Paulo: Loyola, 2003.

HASSARD, J. From functionalism to fragmentation. In: HASSARD, J. (Org.).Sociology and organization theory: positivism, paradigms and postmodernity. Grã-Bretanha: Cambridge, 1995. 49-75 p.

; PARKER, M. (Org.). Postmodernism and organizations. London: Sage, 1993. 1-23 p.

HICKSON, D. For positivist organization theory. Administrative Science Quarterly, v. 43, n. 4, p. 950-953, 1998.

HODGSON, D. For positivist organization theory. Management Learning, v. 29, n. 2, p. 231-233, jun.1998.

JAPIASSU, H. O sonho transdisciplinar. In: COLÓQUIO INTERNACIONAL DE ESPISTEMOLOGIA E SOCIOLOGIA DA CIÊNCIA DA ADMINISTRAÇÃO, 3., 2013, Florianópolis. Conferência de abertura, Florianópolis, 2013. Documento não publicado.

KUHN, T. A estrutura das revoluções científicas. São Paulo: Perspectiva, 2003.

LIPOVETSKY, G. A era do vazio: ensaios sobre o individualismo contemporâneo. São Paulo: Manole, 2005.

MARTINS, A. G. S.; MARTINS, C. Os estudos organizacionais e os gigantes: que emancipação está em jogo nos estudos críticos em administração? COLÓQUIO INTERNACIONAL DE ESPISTEMOLOGIA E SOCIOLOGIA DA CIÊNCIA DA ADMINISTRAÇÃO, 2., Florianópolis, 2012

MARX, K. O capital. Rio de Janeiro: Bertrand Brasil, 1989.

MENEGHETTI, F. K. Pensamento crítico e teoria das organizações. In: ENCONTRO DA ANPAD,28, 2004. Curitiba. Anais... Curitiba, 2004. 1 CD-ROM.

MEYER, A. D.; TSUI, A. S.; HININGS, C. R. Guest co-editors' introduction: configurational approaches to organizational analysis. Academy of Management Journal, v. 36, n. 6, p. 1175-1995, 1993.

MORGAN, G. Paradigmas, metáforas e resolução de quebra-cabeças na teoria das organizações. Revista de Administração de Empresas, v. 45, n. 1, p. 58-71, jan./mar. 2005.

MORIN, E. Introdução ao pensamento complexo. Tradução: Dulce Matos. Lisboa: Instituto Piaget, 1991.

MOTTA, F. C. P. Burocracia e autogestão: a proposta de Proudhon. São Paulo: Brasiliense, 1981.

PARKER, M. Critique in the name of what? Postmodernism and critical approaches to organization. Organization Studies, v. 16, n. 4, p. 553-612, Fall. 1995.

PAULA, A. P. P. Guerreiro Ramos: resgatando o pensamento de um sociólogo crítico das organizações. Organização \& Sociedade, v. 14, n. 40, p. 169-188, jan./mar., 2007.

; MARANHÃO, C. M. S. A. Opressão e resistência nos estudos organizacionais críticos; considerações acerca dos discursos da servidão voluntária e da pedagogia do oprimido. Organização \& Sociedade, v. 16, n. 50, p. 463-477, jul./set. 2009. 
PERROW, C. Pfeffer slips. Academy of Management Review, v. 19, n. 2, p. 191-194, 1994.

PFEFFER, J. Barriers to the advance of organizational science: paradigm development as a dependent variable. Academy of Management Review, v. 18, n. 4, p. 599-620, 1993.

RAMOS, A. G. A redução sociológica: introdução ao estudo da razão sociológica. 2. ed. Rio de Janeiro: Tempo Brasileiro, 1965.

. A nova ciência das organizações: uma reconceituação da riqueza das nações. Rio de Janeiro: FGV, 1981.

\section{4.}

. Modelos de homem e teoria administrativa. Revista de Administração Pública, v. 18, n. 2, p. 3-12, abr./jun.,

REED, M. Teorização organizacional: um campo historicamente contestado. In: CLEGG, S. et al. (Org.). Handbook de Estudos Organizacionais. São Paulo: Atlas, 1998.

SANTANA, W. G. P.; GOMES, A. F. Por uma convivência (não tão) harmônica entre nos estudos organizacionais. In: ENCONTRO DA ASSOCIAÇÃO NACIONAL DE PÓS-GRADUAÇÃO E PESQUISA EM ADMINISTRAÇÃO (EnANPAD), 31., 2007. Rio de Janeiro. Anais... Rio de Janeiro: [s.n.], 2007. 1 CD-ROM.

SCHULTZ, M.; HATCH, M. J. Living with multiple paradigms: the case of paradigm interplay in organizational culture studies. Academy of Management Review, v. 21, n. 2, p. 529-557, 1996.

SOUSA SANTOS, B. Para um novo senso comum: ciência, o direito e a política na transição paradigmática. São Paulo: Cortez, 2000. v. 1.

. A globalização e as ciências sociais. São Paulo: Cortez, 2005.

TENÓRIO, F. G. Flexibilização organizacional: mito ou realidade? 2. ed. Rio de Janeiro: Editora FGV, 2002.

. Tem razão a administração? Ensaios de teoria organizacional. 2. ed. Ijuí: Unijuí, 2004.

. Pensamento crítico versus pensamento tradicional. Cadernos EBAPE.BR, v.7, n. 3, p. 472-491, set. 2009.

VIEIRA PINTO, A. Ciência e existência: problemas filosóficos da pesquisa científica. Rio de Janeiro: Paz e Terra, 1979. 